\title{
Determination of Physicochemical Properties, Heavy Metals and Pesticide Residues of Honey Samples Collected From Walmara, Ethiopia
}

\author{
Deressa Kebebe $^{1^{*}}$, Alemayehu Paulos ${ }^{2}$, Ermias Haile ${ }^{3}$ \\ Department of Chemistry, Hawassa University, Hawassa, Ethiopia
}

*Corresponding Author: Deressa Kebebe, Department of Chemistry, Hawassa University, Hawassa, Ethiopia

\begin{abstract}
This study was conducted to investigate pesticide residues, heavy metals and physicochemical parameters levels in honey samples. In this study, the results of moisture content, electrical conductivity, $\mathrm{pH}$ and ash were $15.15-21.75 \%, 0.45-1.55 \mathrm{mScm}^{-1}, 3.50-4.50$, and $0.18-0.80 \%$ and that of $\mathrm{Fe}, \mathrm{Zn}, \mathrm{Cu}, \mathrm{Pb}, \mathrm{Cd}$, $\mathrm{Ni}$ and $\mathrm{Cr}$ were analyzed by using flame atomic absorption spectrophotometer and the concentrations ranged from 4.87-11.79 $\mu \mathrm{g} / \mathrm{g}, 1.41-6.94 \mu \mathrm{g} / \mathrm{g}, 0.22-1.22 \mu \mathrm{g} / \mathrm{g}, 0.37-0.90 \mu \mathrm{g} / \mathrm{g}, 0.04-0.70 \mu \mathrm{g} / \mathrm{g}, 0.26-0.60 \mu \mathrm{g} / \mathrm{g}$ and $0.16-0.50 \mu \mathrm{g} / \mathrm{g}$ with mean concentration ranges, respectively. All metals were determined by using atomic absorption spectrophotometer except Fe that was determined by using UV-visible spectrophotometer. The percentage recovery for metal analyses was from $85 \%$ to $104 \% . \mathrm{Cd}, \mathrm{Cu}, \mathrm{Cr}$ and $\mathrm{Pb}$ concentrations in honey samples from all sites were not significantly different but $\mathrm{Fe}, \mathrm{Zn}$ and $\mathrm{Ni}$ levels were significantly different at $(p<0.05)$. Pesticide residues in the honey samples were determined by using gas chromatography coupled with mass spectrometer technique. The residues in all samples were found to be below detection limits. The detection limits range was from 0.001 to $0.017 \mathrm{ng} / \mathrm{g}$ for the residues analyzed while the recovery percentages were range from 75-105\%. Most trace metals and all residues have been found to be within the acceptable range set by national and international standards except Pb and Cd contents in some samples which need further study in the future.
\end{abstract}

Keywords: Flame Atomic Absorption Spectrophotometry, Gas Chromatography-Mass Spectrometry, Heavy Metals, Honey, Pesticide Residue.

\section{INTRODUCTION}

Bee honey is syrupy and viscous substance that produced by honeybees from the nectar of flowers or from the secretion of living parts of plants, in which honeybees transform through enzymatic activity and store it in wax structures called honeycombs until maturation (Adenekan, 2010, Awad and Elgornazi, 2016) should be safe for all consumers and pollinators. It has been used by humans since ancient times in various foodstuffs and drinks as a sweetener and flavoring (Kowsalya, 2012, Omoya et al, 2014).It has also medicinal and therapeutic effects (Eyobel et al., 2017).

Since the forage area of the hive is very large (more than $7 \mathrm{~km}^{2}$ ) and the bees come in contact not only with air but also with soil and water, the concentration of heavy metals in honey reflects their amount in the whole region. Therefore, honey has been recognized as a biological indicator of environmental pollution (Przybylowski, 2001). Determination of heavy metals in honey is of high interest mainly for quality control and nutritional aspect (Buldini, 2001).

Chemical pesticides are conventionally synthetic materials that directly kill or inactivate the pest (Rama et al., 2011). Depending on their chemical properties they can enter the organism, bio accumulate in food chains and consequently influence also human health (PAN Europe, 2010). Pesticides use is usually accompanied with deleterious environmental and public health effects. Pesticides hold a unique position among environmental contaminants due to their high biological activity and toxicity (acute and chronic). Although some pesticides are described to be selective in their modes of action, their selectivity is only limited to test animals. Thus pesticides can be best described as biocides i.e., capable of harming all forms of life other than the target pest (Zacharia, 2011). 
The study district is identified as one of the potential areas for beekeeping in the country and honey is an important source of income for farmers in the area. But it is exposed to pesticides that may be released from floricultural industries and other agricultural activities. In addition, there are floriculture industries and factories that may release trace metals to the area because their applications are highly increasing from time to time (Belay, 2015).Therefore, the objective of this study was to determine physicochemical properties, pesticides residues and heavy metals of honey and comparing their levels with international and national standards.

\section{Methods AND Materials}

\subsection{Study Area Description}

The study was under taken in Walmara district in central highland part of Ethiopia. The district total land area is 80,927 hectares. This district is located at $25 \mathrm{Km}$ to the west of Finfinne $\left(8.5^{\circ}-9.5^{\circ} \mathrm{N}\right.$ and $38.4^{\circ}-39.2^{\circ} \mathrm{E}$ ) with altitude of $2000-3380 \mathrm{~m}$. It is bordered by Finfinne to the East; Ejere district to the West, Sululta district to the North, Sebeta Hawas district from the south and its weather condition is classified as $39 \%$ woinadega and $61 \%$ dega. The district has 1,853 traditional, 870 transitional, 843 modern beehives. The yields gained was $20 \mathrm{Kg}, 15 \mathrm{Kg}$ and $5 \mathrm{Kg}$ per hive per year from modern, transitional and traditional, respectively.

\subsection{Sample Collections, Storages and Pretreatments}

Unprocessed representative honey subsamples, twenty in number were collected using purposive sampling technique from 20 selected beekeepers in clean honey sampling plastic jars. Honey samples of each weighing about $1 \mathrm{~kg}$ were collected directly from beekeepers during active season from January to May 2018 and then transferred to laboratory and preserved.

Four composite samples (a sample from five apiaries) were mixed and homogenized to determine pesticides while 8 composited honey samples from similar sites were used to determine trace metals and physicochemical properties. The samples were placed in contaminant free polyethene plastic container labeled and stored in refrigerator at $-20^{\circ} \mathrm{C}$ until analyses to determine pesticide residues in the four samples.

\subsection{Equipments and Reagents}

\subsubsection{Equipments}

The laboratory apparatus that was used during the study include: measuring cylinders, funnel, filter papers, pipettes and micropipettes (Pyrex, USA) to dilute sample solutions and prepare standard solutions, round bottom flasks $250 \mathrm{~mL}$ fitted with reflux condenser were used in heating mantle (BI Barnstead Electro thermal, EC, UK) to digest honey samples, spiked honey samples and blank solutions as well as refrigerator to keep the collected samples and digested samples until analysis and digital Analytical Balance (Mettler Toledo, Model AG250, Switzerland with $\pm 0.0001 \mathrm{~g}$ ) to weigh honey samples.

An Agilent 7890B gas chromatograph connected to an Agilent 5977AMSD system equipped with an auto sampler G4513A, GC/MS (Agilent Technologies, USA) were used for detection of pesticide residues.

\subsubsection{Reagents}

All Reagents and chemicals used in the analysis were of Analytical Grade. A combination of concentrated 69-72\% $\mathrm{HNO}_{3}$ (Unichem) and $30 \% \mathrm{H}_{2} \mathrm{O}_{2}$ (UNI-Chem.), $\mathrm{H}_{2} \mathrm{SO}_{4} 98 \%$ (Loba) were used in digestion of honey samples, blank and spiked solutions at optimum condition. Deionized water was used during the research for sample preparation, dilution and rinsing apparatus prior to analysis. Hydroquinone 99\% (Kiran light Laboratory), 1,10-phenanthroline, sodium acetate trihydrate 99\%, ferrous ammonium sulfate hex hydrate $98 \%$ were used for the determination of iron metal in the honey sample.

Pesticide standards were used from JIJE Laboratory Services in Addis Ababa in Ethiopia with purity between 98.2 and 99.5\%. Acetonitrile (99.99 \%, Sigma Aldrich, Germany) high-performance liquid chromatography grade were used. Anhydrous magnesium sulfate, acetic acid and sodium acetate was obtained from Merck (China). Ultrapure water was prepared from a Milli-Q system (Millipore, Bedford, MA, USA). 


\subsection{Sample Preparation for Pesticides Analysis}

$5 \mathrm{~g}$ of the honey samples were thoroughly homogenized with $10 \mathrm{ml}$ ultrapure water and the homogenate was transferred into polypropylene centrifuge tube $(50 \mathrm{ml})$. Then it was hand-shaken for 5 minutes. Thereafter, $15 \mathrm{ml}$ of acetonitrile was added and mixed for 2 minutes, and the Quenchers salt kit was added. The samples were immediately hand shaken for 2 minutes and subsequently centrifuged at $3500 \mathrm{rpm}$ for 5 minutes.

Thereafter, $6 \mathrm{ml}$ of supernatant was transferred in a $15 \mathrm{ml}$ DSPE polypropylene tube. The tube was shaken for 30 seconds and subsequently centrifuged at $3500 \mathrm{rpm}$ or 5 minutes. Finally, $0.5 \mathrm{ml}$ of supernatant was taken into glass auto sampler vial (Kurtagićand Čopra-Janićijević, 2016).

AOAC official method 2007.01 was used for analysis of pesticide in the honey samples. In this particular method, the Quenchers method were used for extraction of pesticide from honey samples using a single-step buffered acetonitrile extraction and salting out liquid-liquid partitioning from the water in the sample with $\mathrm{MgSO}_{4}$ (Lehotay, 2007).

\subsection{Physicochemical Analysis of Honey Samples}

\subsubsection{Variation in Honey Color}

Honey color of the samples were measured using Pound color grader (AOAC, 1990). The scale used in the honey industry to describe the color of honey which consists of a wedge of amber-colored glass next to a wedge-shaped cell which is filled with honey.

\subsubsection{Ash Content}

This variable was determined and calculated by adopting the 920, 181 method established by A.O.A.C and the ES (Belouali et al., 2008). Honey sample of $5 \mathrm{~g}$ was weighed accurately into a preweighed porcelain crucible and gently heated on a hot plate until the sample was turned into black and dry. This is to avoid danger of loss by foaming and overflowing that may occur if the sample is directly burnt in muffle furnace. The sample was then ignited at $600^{\circ} \mathrm{C}$ in a furnace (overnight) to constant weight. Then, the samples were cooled in a desiccators and weighed (Rehman et al., 2008).

\subsection{Determination of the $\mathbf{p H}$ and Electrical Conductivity of Honey Samples}

Seventy (70) $\mathrm{ml}$ of deionizer water ( $\mathrm{pH} 7.0$ ) was added to $10 \mathrm{~g}$ of honey and mixed thoroughly to determine $\mathrm{pH}$ and electrical conductivity. Then, after the instrument was calibrated, finally, the $\mathrm{pH}$ and EC were measured directly and the results were recorded.

\subsection{Determination of Moisture Content of Honey Samples}

The moisture content of each honey sample was determined by weighing out $5 \mathrm{~g}$ of the sample and placed it into a pre-weighed aluminum drying dish. The sample was then dried to a constant weight in an oven at $105^{\circ} \mathrm{C}$ for 4 hour under vacuum and its weight taken again.

Moisture content $=\frac{(\mathrm{M} 2-\mathrm{M} 1)}{(\mathrm{M} 1-\mathrm{M} 0)}$

Where: $\mathrm{M}_{0}=$ Weight of aluminum dish, $\mathrm{M} 2=$ Weight of the fresh sample + dish, andM1 = Weight of the dried sample + dish

\subsection{Determination of Metal Contents}

\subsubsection{Digestion of Honey Samples}

In digestion of honey samples blameless optimum condition is obtained when clear solution was formed. Optimum condition was obtained by making different trials using various volumes of solvents, times and temperatures of digestion. Thus, exactly $1 \mathrm{~g}$ of honey sample were accurately weighed on a digital analytical balance and transferred quantitatively into a $250 \mathrm{ml}$ round bottom digestion flask. Four milliliters of $\mathrm{HNO}_{3}$ and three milliliters of $\mathrm{H}_{2} \mathrm{O}_{2}$ were mixed and added to the weighed sample. The solvents were freshly prepared. The sample was swirled gently to homogenize the mixture. Then, it was fitted to a reflux condenser and digested continuously for three hours on a heating mantle by setting the temperature at $240{ }^{\circ} \mathrm{C}$ until clear solution was obtained. Each honey sample was digested in triplicates. Thus, a total of twenty four digests were carried out for the eight honey samples. The samples were then cooled to room temperature for 10 minutes without taking away the condenser from the flask and for 10 minutes more after removing the condenser. Deionizer water was added to the cooled solution to dissolve the solid or semi-solid formed on cooling and to 
minimize dissolution of the filter paper by the digest residue while filtering with what man (No. 42) filter paper. The round bottom flasks were rinsed subsequently with demonized water in to $50 \mathrm{ml}$ volumetric flasks and finally the volumetric flasks were made up to the mark with demonized water.

Reagent blanks digestion also performed for correcting the effect of the blank in parallel with the honey samples keeping all digestion parameters the same. Six reagent blank samples were prepared for the analysis of the honey samples. All the digested samples were stored in a refrigerator until analysis.

Method detection limit which is defined as the minimum concentration of analyte that can be measured and reported with $99 \%$ confidence that the concentration is greater than zero, but it may not necessarily be quantified as an exact value (Harris, 1982) was calculated using the following equation to show applicability of the method developed to determine the metal concentrations in the honey samples at trace levels $(\mu \mathrm{g} / \mathrm{g})$.

$\mathrm{MDL}=3 \mathrm{xSD}$

Where SD and MDL are Method Detection Limit and Standard Deviation, respectively.

Spiking honey samples was carried out to check the efficiency of the developed digestion procedure for each metal determination.

\section{RESULTS AND DISCUSSION}

\subsection{Physicochemical Parameters of Honey}

Physicochemical properties of honey are related to quality of honey. Therefore, checking the safety of current honey produced in the study area is important for consumers and traders of the citizens. In this study three replicates of each honey samples were analyzed for each physicochemical property as shown in the table below.

Table1. Physicochemical properties of honey samples (mean $\pm S D$ )

\begin{tabular}{|c|c|c|c|c|}
\hline $\begin{array}{c}\text { Sampling Site } \\
\text { identity }\end{array}$ & ${ }^{\mathbf{a}} \mathbf{p H}$ value & $\begin{array}{c}{ }^{\mathbf{a}} \text { Electrical conductivity } \\
(\mathbf{m S c m}-\mathbf{1})\end{array}$ & $\begin{array}{c}{ }^{\mathbf{a}} \mathbf{A s h} \text { Content } \\
\mathbf{( w / w ~ \% )}\end{array}$ & $\begin{array}{c}{ }^{\mathbf{a}} \text { Moisture content } \\
\mathbf{( \% )}\end{array}$ \\
\hline WCW1 & $3.50 \pm 0.02$ & $1.35 \pm 0.07$ & $0.68 \pm 0.07$ & $19.35 \pm 1.20$ \\
\hline WC2 & $3.50 \pm 0.01$ & $1.55 \pm 0.24$ & $0.80 \pm 0.14$ & $19.35 \pm 1.20$ \\
\hline WC3 & $3.50 \pm 0.03$ & $0.45 \pm 0.13$ & $0.18 \pm 0.07$ & $21.75 \pm 0.49$ \\
\hline BW4 & $3.55 \pm 0.07$ & $0.51 \pm 0.21$ & $0.21 \pm 0.13$ & $15.65 \pm 0.77$ \\
\hline GL5 & $3.75 \pm 0.07$ & $0.70 \pm 0.35$ & $0.32 \pm 0.02$ & $15.15 \pm 0.49$ \\
\hline GS6 & $3.70 \pm 0.01$ & $0.62 \pm 0.33$ & $0.27 \pm 0.19$ & $17.65 \pm 1.34$ \\
\hline AS7 & $3.90 \pm 0.01$ & $0.56 \pm 0.06$ & $0.24 \pm 0.03$ & $20.95 \pm 0.91$ \\
\hline QL8 & $4.5 \pm 0.001$ & $1.10 \pm 0.02$ & $0.55 \pm 0.01$ & $17.55 \pm 0.91$ \\
\hline
\end{tabular}

${ }^{a}$ is to indicate values are mean \pm SD of triplicate honey samples

Where WCW1, WC2, WC3, BW4, GL5, GS6, AS7 and QL8 are to represent sampling sites of Choke Walmara, Choke Jatani, Choke Gare Jatani, Burka Walmara, Gole Liben, Garasu Sida, Asgori Subba and Qarsa Lafto, respectively.

\subsection{Variation In Honey Color}

The color of honey samples obtained from determination shown variation from extra light amber (WCW1) to dark (QL8) indicating the flora source of honey samples varies from one another even in a district level. The following results were found as shown in Table 2.

Table2. Classification of honey samples based on color intensity

\begin{tabular}{|c|c|c|}
\hline Sample site & ${ }^{\text {a}}$ Pfund reading(mm) & Class of honey color \\
\hline WCW1 & $6.05 \pm 0.14$ & Extra light amber \\
\hline WC2 & $5.35 \pm 0.07$ & Light amber \\
\hline WC3 & $9.65 \pm 0.07$ & Amber \\
\hline BW4 & $9.15 \pm 0.07$ & Amber \\
\hline GL5 & $5.65 \pm 0.07$ & Light amber \\
\hline GS6 & $6.95 \pm 0.07$ & Light amber \\
\hline AS7 & $9.55 \pm 0.07$ & Amber \\
\hline QL8 & $13.10 \pm 0.14$ & Dark \\
\hline
\end{tabular}

a is to indicate values are mean \pm SD of triplicate honey samples, SD is standard deviation 


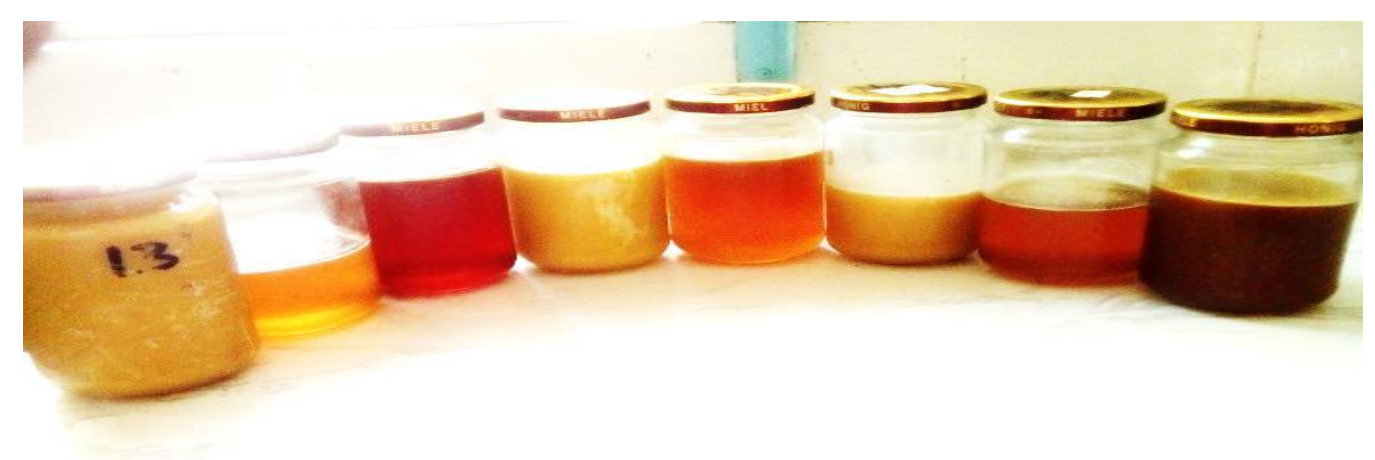

Figure1. Different honey color obtained from the study areas

The honey color shown above indicated that color of honey can be different even if it is observed from a limited area in the same honey harvesting season.

\subsection{Moisture Contents}

The moisture content in the investigated honey samples was found to be in the range of 15.15-21.75\% (Table 1), which are within the limit $(\leq 20 \%)$ recommended by the international quality regulations (Codex, 2001, European Union, 2002) except a sample taken from WC3 site. Generally, the moisture content of GL5 honey recorded the lowest moisture content $(15.15 \pm 0.49 \%)$ among the analyzed samples, followed by BW4 (15.65 \pm 0.77), QL8 (17.55 \pm 0.91$)$, GS6 (17.65 \pm 1.34$)$ and WCW1 and WC2 $(19.35 \pm 1.20 \%)$, while AS7 $(20.95 \pm 0.91 \%)$. Honey sample showed the highest value of moisture content was WC3 $(21.75 \pm 0.49)$.

\subsection{Ash Content}

The highest allowable ash contents of honey according to the specifications of Ethiopian, European and Codex standards are <0.6, <0.6 and $<0.8 \%$, respectively (Codex, 2001, Osman et al, 2007, Europeans union, 2002). Therefore, the ash contents in all analyzed honey samples were below the limit $(0.6 \%)$ except that of WCW1 and WC2 honey samples others allowed by different standards. The highest value of ash content was recorded for WC2 honey samples $(0.80 \%)$, followed by WCW1 $(0.68 \%)$, QL8 (0.55 \%), GL5 (0.32\%), GS6 (0.27\%), AS7 (0.24\%), BW4 (0.21\%) and WC3 (0.18\%).

In this study, it was found that the higher the ash content, the higher the electrical conductivity of the samples. The relationship between ash percentage and electrical conductivity are important because they permit an indirect estimate of mineral content (Fredes and Montenegro, 2006).

\section{5. pH and Electrical conductivity}

The highest electrical conductivity was recorded for WC2 $(1.55 \pm 0.24)$ honey followed by WCW1 (1.35 \pm 0.07$)$, QL8 (1.10 \pm 0.02$)$, GL5 (0.70 \pm 0.35$)$, GS6 (0.62 \pm 0.33$)$, AS7 (0.56 \pm 0.06$)$, BW4 $(0.51 \pm 0.21)$ and WC3 $(0.45 \pm 0.13)$ in $\mathrm{mScm}-1$. These values have linear relation with that of the ash content as expected because the higher ash content is the higher electrical conductivity or vice versa. The maximum electrical conductivity for pure floral honey is $0.8 \mathrm{mScm}^{-1}$ (Revised Codex, 2001). If honey is contaminated with water or saturated sugar solutions, it will give greater conductance than pure honey (Rehman et al., 2008). The electrical conductance of the eight honey samples was found considerably lower than that established by the Codex Alimentations $\left(<0.8 \mathrm{mScm}^{-1}\right)$ except honey samples collected from WCW1, WC2 and QL8 sites (Revised Codex Rev.1, 1987, Rev.2, 2001).

The $\mathrm{pH}$ values of all honey samples were found to be acidic and there was slight $\mathrm{pH}$ difference among the samples analyzed. The mean $\mathrm{pH}$ values recorded were ranged 3.50-4.50 for the eight honey samples. The $\mathrm{pH}$ was also within the accepted range $(3.50-5.50)$ according to the standard (Revised Codex Rev.1, 1987, Rev.2, 2001).

Physicochemical properties analyzed could be summarized by the ranges of each variable as: $\mathrm{pH} 3.50$ 4.50, ash content $0.18-0.80 \%$, moisture content $15.15-21.35 \%$, color $5.35-13.10 \mathrm{~mm}$ on Pfund and electrical conductivity of $0.21-1.55 \mathrm{mScm}^{-1}$. 


\subsection{Determination of metals and discussion on their levels in eight honey samples from eight sites}

One of the aims of this study is to determine the concentration levels of selected trace metals in honey samples collected from the study area. The concentrations of the metals in the eight honey samples were summarized in Figure 2.

Concentration of metals in honey sample from WCW1 had high concentration of $\mathrm{Fe}, \mathrm{Ni}$ and $\mathrm{Zn}$, respectively. The sample collected contains $\mathrm{Fe}$ in the higher amount with concentration of $8.19 \pm 0.40$ $\mu \mathrm{g} / \mathrm{g}$ followed by $\mathrm{Zn}(1.41 \pm 0.01 \mu \mathrm{g} / \mathrm{g}), \mathrm{Pb}(0.90 \pm 0.03 \mu \mathrm{g} / \mathrm{g}), \mathrm{Cu}(0.60 \pm 0.03 \mu \mathrm{g} / \mathrm{g}), \mathrm{Ni}(0.22 \pm 0.02$ $\mu \mathrm{g} / \mathrm{g})$ and $\mathrm{Cr}(0.22 \pm 0.01 \mu \mathrm{g} / \mathrm{g})$ whereas $\mathrm{Cd}(0.13 \pm 0.01 \mu \mathrm{g} / \mathrm{g})$. Non-essential metals such as $\mathrm{Pb}, \mathrm{Cr}$ and $\mathrm{Cu}$ were also found in lower levels. Lead which is poisonous metal was found to be higher than the permissible range which need more study in the future.

Honey sample from WC2 site mean concentrations in the decreasing order from the highest concentration of metal to lowest is: $\mathrm{Fe}(4.87 \pm 1.95 \mu \mathrm{g} / \mathrm{g}), \mathrm{Zn}(2.46 \pm 0.05 \mu \mathrm{g} / \mathrm{g}), \mathrm{Cd}(0.7 \pm 0.01 \mu \mathrm{g} / \mathrm{g}), \mathrm{Ni}$ $(0.48 \pm 0.03 \mu \mathrm{g} / \mathrm{g}), \mathrm{Cu}(0.45 \pm 0.01 \mu \mathrm{g} / \mathrm{g}), \mathrm{Cr}(0.41 \pm 0.03 \mu \mathrm{g} / \mathrm{g})$ and $\mathrm{Pb}(0.37 \pm 0.02 \mu \mathrm{g} / \mathrm{g})$. This sample also contains high concentration of Fe. The sample is also rich in essential metal $\mathrm{Zn}$. This site honey contained highest amount of non-essential metal $\mathrm{Cd}$ that is higher than the permissible (WHO, 1999). The metals concentration levels from highest to lowest is $\mathrm{Fe}>\mathrm{Zn}>\mathrm{Cd}>\mathrm{Ni}>\mathrm{Cu}>\mathrm{Cr}>\mathrm{Pb}$ for the sample from the site WW2.

The third study site of honey sample WC3 contains also Fe $(7.08 \pm 3.52 \mu \mathrm{g} / \mathrm{g})$, followed by $\mathrm{Zn}$ $(1.74 \pm 0.03 \mu \mathrm{g} / \mathrm{g}), \mathrm{Cu}(0.53 \pm 0.02 \mu \mathrm{g} / \mathrm{g}), \mathrm{Cr}(0.41 \pm 0.01 \mu \mathrm{g} / \mathrm{g}), \mathrm{Pb}(0.39 \pm 0.02 \mu \mathrm{g} / \mathrm{g}), \mathrm{Ni}(0.29 \pm 0.01 \mu \mathrm{g} / \mathrm{g})$ and $\mathrm{Cd}(0.05 \pm 0.01 \mu \mathrm{g} / \mathrm{g})$ with the least concentration level. Honey sample from this site relatively shown less concentration of the metals. On-essential metals $\mathrm{Pb}$ and $\mathrm{Cd}$ were found to be slight amount in this sample. The honey sample from this site was found to be rich in essential metals of Fe and $\mathrm{Zn}$.

The fourth honey sample studied was collected from BW4 site. The concentrations of the metals for this honey were found in the following decreasing order: Fe $(6.24 \pm 0.78 \mu \mathrm{g} / \mathrm{g}), \mathrm{Zn}(1.47 \pm 0.01 \mu \mathrm{g} / \mathrm{g})$, $\mathrm{Ni}(1.22 \pm 0.06 \mu \mathrm{g} / \mathrm{g}), \mathrm{Pb}(0.49 \pm 0.03 \mu \mathrm{g} / \mathrm{g}), \mathrm{Cr}(0.26 \pm 0.02 \mu \mathrm{g} / \mathrm{g}), \mathrm{Cu}(0.26 \pm 0.01 \mu \mathrm{g} / \mathrm{g})$ and $\mathrm{Cd}$ $(0.07 \pm 0.01 \mu \mathrm{g} / \mathrm{g})$. The sample from this site had high concentration of essential metals ( $\mathrm{Fe}, \mathrm{Zn}$ and $\mathrm{Ni})$. The order of concentration of these metals in decreasing order: $\mathrm{Fe}>\mathrm{Zn}>\mathrm{Ni}$ for essential metals and $\mathrm{Pb}>\mathrm{Cu}=\mathrm{Cr}>\mathrm{Cd}$ for non-essential metals.

Samples from GL5 site honey was found with the least amount of the corresponding metals except for the metals $\mathrm{Zn}$ and $\mathrm{Fe}$. The concentrations of the metals for this honey were found in the following decreasing order: $\mathrm{Fe}(6.23 \pm 0.40 \mu \mathrm{g} / \mathrm{g}), \mathrm{Zn}(1.57 \pm 0.06 \mu \mathrm{g} / \mathrm{g}), \mathrm{Ni}(0.83 \pm 0.03 \mu \mathrm{g} / \mathrm{g}), \mathrm{Pb}(0.65 \pm 0.03$ $\mu \mathrm{g} / \mathrm{g}), \mathrm{Cu}(0.42 \pm 0.01 \mu \mathrm{g} / \mathrm{g}), \mathrm{Cr}(0.38 \pm 0.01)$ and $\mathrm{Cd}(0.04 \pm 0.01 \mu \mathrm{g} / \mathrm{g})$.

Honey samples from GS6 study site shown the highest amount of the $\mathrm{Zn}$ metal content. The concentrations of the metals for this honey were found in the following decreasing order: $\mathrm{Fe}$ $(10.59 \pm 2.35 \mu \mathrm{g} / \mathrm{g}), \mathrm{Zn}(6.94 \pm 0.32 \mu \mathrm{g} / \mathrm{g}), \mathrm{Ni}(0.61 \pm 0.04 \mu \mathrm{g} / \mathrm{g}), \mathrm{Pb}(0.59 \pm 0.01 \mu \mathrm{g} / \mathrm{g}), \mathrm{Cr}(0.50 \pm 0.02$ $\mu \mathrm{g} / \mathrm{g}), \mathrm{Cu}(0.44 \pm 0.01 \mu \mathrm{g} / \mathrm{g})$ and $\mathrm{Cd}(0.25 \pm 0.01 \mu \mathrm{g} / \mathrm{g})$.

The honey sample from AS7 study area was found with the least amount of $\mathrm{Cu}$ and one of the highest Fe metals levels. The concentrations of the metals for this honey were found in the following decreasing order: $\mathrm{Fe}(9.57 \pm 0.78 \mu \mathrm{g} / \mathrm{g}), \mathrm{Zn}(3.60 \pm 0.05 \mu \mathrm{g} / \mathrm{g}), \mathrm{Ni}(0.76 \pm 0.01 \mu \mathrm{g} / \mathrm{g}), \mathrm{Pb}(0.66 \pm 0.02$ $\mu \mathrm{g} / \mathrm{g}), \mathrm{Cd}(0.65 \pm 0.06 \mu \mathrm{g} / \mathrm{g}), \mathrm{Cu}(0.36 \pm 0.01 \mu \mathrm{g} / \mathrm{g})$ and $\mathrm{Cr}(0.16 \pm 0.01 \mu \mathrm{g} / \mathrm{g})$.

Honey sample from QL8 site was found with the highest amount of Fe metal content. The concentrations of the metals for this honey were found in the following decreasing order: $\mathrm{Fe}(11.79 \pm$ $0.39 \mu \mathrm{g} / \mathrm{g}), \mathrm{Zn}(3.82 \pm 0.32 \mu \mathrm{g} / \mathrm{g}), \mathrm{Pb}(0.57 \pm 0.01 \mu \mathrm{g} / \mathrm{g}), \mathrm{Ni}(0.40 \pm 0.04 \mu \mathrm{g} / \mathrm{g}), \mathrm{Cu}(0.38 \pm 0.02 \mu \mathrm{g} / \mathrm{g})$, and $\mathrm{Cr}(0.24 \pm 0.01)$ and $\mathrm{Cd}(0.11 \pm 0.01 \mu \mathrm{g} / \mathrm{g})$. The non-essential metals such as $\mathrm{Cd}$ and $\mathrm{Pb}$ levels are higher in WC2 and WCW1 samples than the permissible concentration, respectively. The level of this metals was found to be $\mathrm{Fe}>\mathrm{Zn}>\mathrm{Pb}>\mathrm{Ni}>\mathrm{Cu}>\mathrm{Cr}>\mathrm{Cd}$ from highest to lowest level of concentrations.

The non-essential toxic metal Cd was slightly high in two honey samples where as in other rest honey samples below the maximum values allowed. The level of $\mathrm{Cu}$ metal analyzed in the eight honey samples were found below maximum tolerable limits (WHO, 1999). 


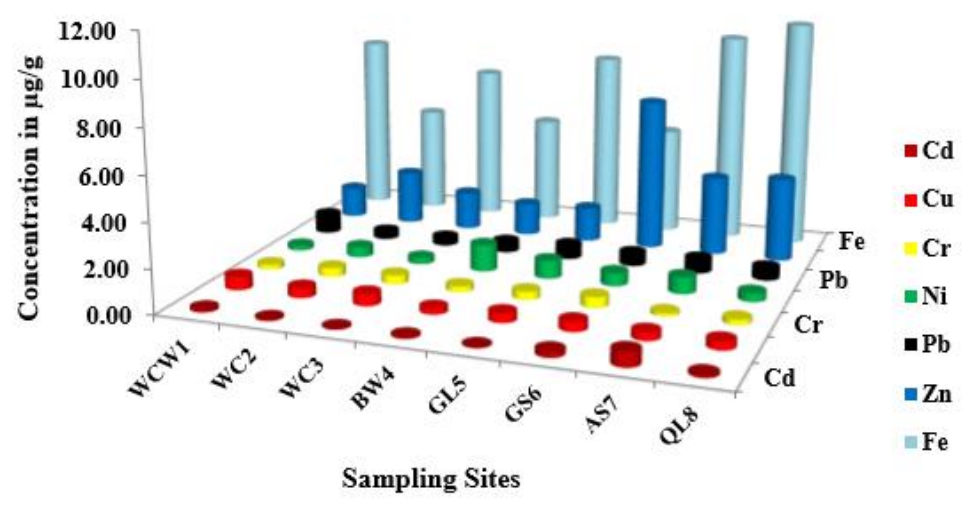

Figure2. Level of metals concentrations in honey samples from the eight study areas

Where WCW1, WC2, WC3, BW4, GL5, GS6, AS7 and QL8 are abbreviations of Walmara Choke one, Walmara Choke Jatani, Walmara Choke Jatani one, Burka Walmara, GoleLiben, GarasuSida and QarsaLafto sampling sites of the study areas.

The range of the trace metals mentioned as follow: $\mathrm{Fe}$ was found to be highest with mean concentration ranging from $\mathrm{Fe}(4.87$ to $11.79 \mu \mathrm{g} / \mathrm{g}$ ) followed by $\mathrm{Zn}(1.41$ to $6.94 \mu \mathrm{g} / \mathrm{g}), \mathrm{Cu}(0.22$ to$1.22 \mu \mathrm{g} / \mathrm{g}), \mathrm{Pb}(0.37-0.90 \mu \mathrm{g} / \mathrm{g}), \mathrm{Cd}(0.04-0.70 \mu \mathrm{g} / \mathrm{g})$, Ni with mean concentration range of $(0.26-$ $0.60 \mu \mathrm{g} / \mathrm{g})$ and $\mathrm{Cr}(0.16-0.50 \mu \mathrm{g} / \mathrm{g})$.

These results show that there is considerable variation in metal contents among honey samples of different study sites. The dissimilarity is most likely due to the floral type, the botanical origin, storage conditions, soil types, materials used to process, anthropogenic factors and so on.

\subsection{Comparison of the results of metals concentrations and Physicochemical properties with reported Values}

There can be unlikeness in sampling, sample preparation and analysis using various methods even though various chemical analysis target to a similar objective. Bearing in mind all these, the result of the present study can be compared to the findings of other study results. Different reports indicated that the metal content, moisture content, color, EC, $\mathrm{pH}$ and ash content are different for honey of different botanical origins. The comparisons made for heavy metals contents, $\mathrm{pH}$ values, EC and ash content are shown in table $3,4,5$ and 6 , respectively.

Table 3 shows that the concentration level of $\mathrm{Cd}(0.7 \mu \mathrm{g} / \mathrm{g})$ is higher than the WHO/FAO permissible levels in sample from AS7 site. Two samples (WCW1 and AS7 honey) were higher in $\mathrm{Pb}$ concentration than the permissible level of WHO. This may be due to the samples were collected from cement factory area. The other six samples are in a good agreement with most of the results reported from different countries (WHO, 1999). Except honey from WC2 and AS7, the other analyzed non-essential metal was found lower than most of the reported results.

Table 3. Metals concentration $(\mu \mathrm{g} / \mathrm{g}$ ) comparison of the current study with other reported values

\begin{tabular}{|c|c|c|c|c|c|c|c|}
\hline \multirow{2}{*}{ Metals } & \multicolumn{7}{|c|}{ Country and their reported metals level ranges } \\
\cline { 2 - 8 } & WHO/FAO & Brazil & Chile & Pakistan & Switzerland & Venezuela & Ethiopia \\
\hline $\mathrm{Cd}$ & 0.25 & & & & & & \\
\hline $\mathrm{Cr}$ & & & $0.03-1.92$ & & $0.001-0.03$ & & $0.04-0.70$ \\
\hline $\mathrm{Cu}$ & 2 & & & & & & $0.22-1.50$ \\
\hline $\mathrm{Fe}$ & & $1.5-6.24$ & $0.1-6.36$ & $4.35-7.54$ & $0.136-9.85$ & $1.1-5.2$ & $4.87-11.79$ \\
\hline $\mathrm{Ni}$ & & & $0.01-1.04$ & $1.02-1.4$ & $0.001-1.966$ & & $0.26-0.60$ \\
\hline $\mathrm{Pb}$ & 0.5 & & & & & & $0.37-0.90$ \\
\hline $\mathrm{Zn}$ & & & $0.01-4.73$ & $1.98-2.94$ & $0.016-4.133$ & $1.1-24.2$ & $1.41-6.94$ \\
\hline $\begin{array}{c}\text { Refere } \\
\text { nce }\end{array}$ & $(\mathrm{WHO}, 1999)$ & $\begin{array}{c}\text { (Soares, } \\
\text { (2008) }\end{array}$ & $\begin{array}{c}\text { (Fredes, } \\
2006)\end{array}$ & $\begin{array}{c}\text { (Rehman, } \\
\text { 2008) }\end{array}$ & $\begin{array}{c}\text { (Bogdanov, } \\
\text { 2007) }\end{array}$ & $\begin{array}{c}\text { (Ferrer, } \\
2004)\end{array}$ & $\begin{array}{c}\text { Present } \\
\text { study }\end{array}$ \\
\hline
\end{tabular}

The honey samples from WCW1, AS7, GL5, GS6 and QL8 have higher Pb sites metal concentration than the permissible level. This might require further studies on the geographical origin of the samples to aid to find out probable sources of heavy metal contamination and vegetation of the area from where the honey was originated. 
Determination of Physicochemical Properties, Heavy Metals and Pesticide Residues of Honey Samples Collected From Walmara, Ethiopia

Table 4. Reports of pH of honey from different countries

\begin{tabular}{|c|c|c|}
\hline Country & pH & Reference \\
\hline Saudi Arabia & $3.88-4.25$ & (Osman, 2007) \\
\hline Czech Republic & $3.70-4.40$ & (Elechovska and Vorlova, 2001) \\
\hline Chile & $3.79-5.08$ & (Feredes, 2006) \\
\hline Croatia & $3.79-5.08$ & (Daniel, 2005) \\
\hline Argentina & $4.21-5.55$ & (Naab, 2008) \\
\hline Present study & $3.50-4.50$ & \\
\hline
\end{tabular}

Table 5. Reports of electrical conductivity of honey from different countries

\begin{tabular}{|c|c|c|}
\hline Country & EC/mScm & Reference \\
\hline Saudi Arabia & $0.139-0.398$ & ( Osman, 2007) \\
\hline Czech Republic & $0.239-0.613$ & ( Elechovska, 2001) \\
\hline Algeria & $0.21-1.24$ & (Makhloufi, 2007) \\
\hline Chile & $0.11-0.97$ & (Fredes, 2006) \\
\hline Brazil & $0.25-1.07$ & (Soares, 2008) \\
\hline Switzerland & $0.10-0.50$ & (Danolan, 2007) \\
\hline Croatia & $0.45-0.89$ & (Naab, 2008) \\
\hline Argentina & $0.113-0.278$ & \\
\hline (Ethiopia) present study & $0.45-1.55$ & \\
\hline
\end{tabular}

Table6 below shows the ash contents of this study and that of other countries to compare the properties.

Table 6. Reports of ash contents of honey from different countries

\begin{tabular}{|c|c|c|}
\hline Country & Ash content(\%w/w) & Reference \\
\hline Saudi Arabia & $0.11-3.398$ & (Osman, 2007) \\
\hline Brazil & $0.04-0.76$ & (Soares,2008) \\
\hline Venezuela & $0.352-0.643$ & (Ferrer, 2004) \\
\hline Ethiopia & $0.18-0.80$ & (present study) \\
\hline
\end{tabular}

The present studied physicochemical properties: $\mathrm{pH}, \mathrm{EC}$, moisture and ash content are also in a good agreement with the reported results from different countries in the world. The ash content found in this study is higher than all the countries except Saudi Arabia honey ash content.

\subsection{Determination of Pesticide Residues Levels in Honey Samples}

Another aim of this study was to determine the level of pesticides in honey samples collected from selected areas of Walmara district of Oromia Special Zone Surrounding Finfinneto get information on the residues levels in the bee products using GC/MS technique.

Pesticide residues analyzed in the AS, BWB, GSL and WC honey samples were aldrin, $\alpha$-BHC, $\beta$ BHC, $\gamma$-BHC, $\delta$-BHC, P,P'DDD, P,P'DDE, P,P'DDT, O, P-DDD, endosulfan, endrine, heptachlor, heptachlor exo-epoxide and diaznone. According to this study the residues were found to be lower than the detection limits. The detection limits ranged from 0.001 to $0.017 \mathrm{ng} / \mathrm{g}$ for the residues analyzed while the recovery percentages were range from 75-105\%.

Since 1 September 2008 the European Commission has set new MRLs, which mostly are between 10 and $50 \mathrm{ng} \cdot \mathrm{g}-1$ in honey (Blasco et al., 2011). According to a report, of 90 analyzed samples, pesticide residue monitoring showed that $44.4 \%$ of the samples contained no detectable residues of the target pesticides (FawzyEissa et al., 2014). Fortunately, results of this study revealed that the honey samples collected from the study area were free of the analyzed pesticide residues. Therefore, the honey from the study area is safe for consumption.

Table7. Pesticide residue in analyzed honey samples $<N D$ means below the detection limit

\begin{tabular}{|c|c|c|c|c|c|}
\hline \multirow[t]{3}{*}{ Pesticides } & \multicolumn{5}{|c|}{ Name of sampling area was Walmara district } \\
\hline & \multicolumn{4}{|c|}{ Levels of pesticides residues in ppb } & \multirow[t]{2}{*}{ LOD (ng/g) } \\
\hline & $\mathbf{A S}$ & BWB & GSL & WC & \\
\hline Aldrin & ND & ND & ND & ND & 0.003 \\
\hline$\alpha-\mathrm{BHC}$ & ND & ND & ND & ND & 0.001 \\
\hline$\beta-\mathrm{BHC}$ & ND & ND & ND & ND & 0.005 \\
\hline
\end{tabular}


Determination of Physicochemical Properties, Heavy Metals and Pesticide Residues of Honey Samples Collected From Walmara, Ethiopia

\begin{tabular}{|c|c|c|c|c|c|}
\hline$\gamma$-BHC & ND & ND & ND & ND & 0.002 \\
\hline$\delta$-BHC & ND & ND & ND & ND & 0.017 \\
\hline P,P'DDD & ND & ND & ND & ND & 0.005 \\
\hline P,P'DDE & ND & ND & ND & ND & 0.002 \\
\hline P,P'DDT & ND & ND & ND & ND & 0.004 \\
\hline Endosulfan II & ND & ND & ND & ND & 0.002 \\
\hline Endrine & ND & ND & ND & ND & 0.005 \\
\hline Heptachlor & ND & ND & ND & ND & 0.001 \\
\hline Heptachlor Exo-epoxide & ND & ND & ND & ND & 0.001 \\
\hline Diaznon & ND & ND & ND & ND & 0.003 \\
\hline O, P-DDD & ND & ND & ND & ND & 0.007 \\
\hline
\end{tabular}

Where LOD is Limit of detect, AS Asgori Suba, BWB Burka Walmara and GSL Garasu Sida study sites

Though the results shown that there are no important pesticide residues in the analyzed samples, the fact no biocides were detected or not exceeded the admitted level does not necessarily mean that farmers are not using pesticides because some time honeybees can make biological transformation/detoxification of toxic substances and extract through their feces to sustain their life.

Estimated daily intake (EDI) is determined for the detected pesticide residues in the honey sample following the international guidelines WHO (1997) and FAO (2002)by using the next equation:

$\mathrm{EDI}=\Sigma \mathrm{C} \times \mathrm{F} /(\mathrm{D} \times \mathrm{W})$

Where, $\mathrm{C}$ is the mean of pesticide residues concentration in honey $(\mu \mathrm{g} / \mathrm{kg}), \mathrm{F}$ is mean annual intake of honey per person ( $2 \mathrm{~kg}$ per person approximately), $\mathrm{D}$ is number of days in a year (365), and $\mathrm{W}$ is mean body weight $(60 \mathrm{~kg})$.

Since there were no detected residues in the samples, the estimated daily intakes of pesticides in the samples less than detection limit were below the ADIs, which may indicate that honey consumption has a negligible influence to health risk. If the hazard index of the pesticide residue is lower than unity, then the consumer is considered to be adequately safe. The hazard index values showed that all the intakes of pesticide residues remain clearly below the safe limit.

\section{CONCLuSion}

The physicochemical parameters analyzed could be summarized by the ranges of each variable as: $\mathrm{pH}$ 3.5-4.50, ash content $0.18-0.80 \%$, moisture content $15.15-21.35 \%$ and electrical conductivity of 0.21 $1.55 \mathrm{mScm}^{-1}$.

A good percentage recovery for metals analyzed was obtained (85-104\%). The study also showed the analyzed metals were found to follow the decreasing order: $\mathrm{Fe}>\mathrm{Zn}>\mathrm{Ni}>\mathrm{Pb}>\mathrm{Cu}>\mathrm{Cr}>\mathrm{Cd}$. All metals are in acceptable ranges but some of them were slightly higher than the permissible levels of national and international standards. Even though, the ranges of obtained parameters are in acceptable by different national and international standards, some values are slightly higher than the standards. This implies that the expansion of floriculture and factories in the area should control their pollutants that may increase metals level and making aware the owners and the releasers of the metals by concerning body is important and timely.

Pesticide residues were below detection limit. Therefore, it can be stated that the honey from the study area is safeto consumers and bees of the area but conforming the results using more sensitive analytical instruments including the remaining parameters is important in the future.

\section{ACKNOWLEDGEMENT}

This research was supported by Oromia Agricultural Research Institute and Hawassa University. In addition, I say thank you to all researchers I used their work to support my work.

\section{REFERENCES}

[1] Adenekan, et.al. (2010). Physico-chemical and Microbiological Properties of Honey Samples Obtained from Ibadan. 2, 104.

[2] AOAC. (1990). Official Methods of Analysis. 15th edition. Arlington, VA: AOAC, 1990.

[3] Awad, M. H., Elgornazi, A. M. (2016). Physicochemical Characterization of Honey from KasrKhiar and Garaboli Areas-Libya., 6, 12. 
[4] Belay Abebe. (2015). Survey on Major Honey Bee Pests and Predators in Oromia Special Zone Surrounding Finfine in Walmara District, Jimma University College of Agriculture and Veterinary Medicine, School of Veterinary Medicine. 65B.

[5] Belouali H., Bouaka M., Hakkou A. (2008). Determination of some major and minor elements in the East of Morocco honeys through inductively coupled plasma optical emission spectrometry, Apiacta, 43, 17.

[6] Blasco, C., Vazquez-Roig, P., Onghena, M., Masia, A., Picó, Y. (2011). Analysis of Insecticides in Honey by Liquid Chromatography-ion Trap-mass Spectrometry: Comparison of Different Extraction Procedures. A, 1218, 4901.

[7] Bogdanov S., Haldimann M., Luginbühl W., Gallmann P. (2007). Minerals in honey environmental, geographical and botanical aspects, Journal of Apicultural Research and Bee World, 46, 275

[8] Buldini P.L., Cavalli, S., Mevoli, A. (2001), 73, 487.

[9] Codex Alimentarius (2001). Revised Codex Standard for Honey, Codex Stan. 12-1981, Rev. 1 (1987), Rev. 2 (2001), 12, 7.

[10] Daniel K., Lljiljana P., Dragan B., Frane č., Ivan C. (2005). Palynological and physicochemical characterisation of Croatian honeys, 467

[11] Elechovska O. and Vorlova 1. (2001). Groups of honey - physicochemical properties and heavy metals, $70: 91$

[12] European Union (2002). Council Directive 2001/110/EC of 20th, December 2001 relating to honey, L10, 52.

[13] EyobelMulugeta, Wodaje Addis, Lemessa Benti, Miresa Tadese. (2017). Physicochemical Characterization and Pesticide Residue Analysis of Honey Produced in West Shewa Zone, Oromia Region, Ethiopia. American Journal of Applied Chemistry. 5, 109.

[14] FAO (2002). Submission and evaluation of pesticide residues data for the estimation of maximum residue levels in food and feed ( $1^{\text {st }}$ Ed.). Rome: Food and Agricul ture Organization http://www. fao.org/ag/ AGP/AGPP/Pesticid/p.htm.

[15] Fawzy et.al. (2014). Determining Pesticide Residues in Honey and their Potential Risk to Consumers, 5, 1575-1576

[16] Ferrer B. S., Rodrguez G. O., M.artnez J., Mordan M. (2004). Mineral content of the honey produced in Zulia state. Venezuela, 54, 348

[17] Fredes, C. and Montenegro, G. (2006). Heavy metal and other trace elements contents in Chilean honey" Ciencia e Investigacion Agrarian 33, 58.

[18] Harris, D.C. (1982). Quantitative Chemical Analysis, 4 th ed., W.H. Freeman and Company, New York, 84.

[19] Joint FAO/WHO. (1999). Expert committee on food additives. Rome, Italy: Summary and conclusions, 53rd meeting 1-10.

[20] Kurtagić, H.andČopra-Janićijević, A. (2016). Determination of Pesticide Residues in Honey using GC-MS Technique, 46, 39.

[21] Lehotay S. J., (2007). Determination of Pesticide Residues in Foods by Acetonitrile Extraction and Partitioning with Magnesium Sulfate: Collaborative Study, 90, 485

[22] Makhloufi C., Schweitzer P., Azouzi B., Oddo L.P., Choukri A., Hocine L., D’Albore G. R. (2007). Some Properties of Algerian Honey, apiacta, 42, 80.

[23] Naab O. A., Tamame1 M. A., Caccavari M. A. (2008). Palynological and physicochemical characteristics of three unifloral honey types from central Argentina, Spanish, 6, 566.

[24] Omoya, F. O.; Ijabadeniyi, O. A.; Ogonnoh, O. B. (2014). Physicochemical Properties of Honey Samples from Ondo State, Nigeria, and their Bioactivity against Spoilage and Patho

[25] Osman, K. A. Al-Doghairi, M. A. Al-Rehiayani, S. Helal, M. I. D. (2007). Mineral contents and physicochemical properties of natural honey produced in Al-Qassim region, Saudi Arabia, 5, 14.

[26] Przybylowski, P., Wilczynska, A. (2001). Honey as an environmental marker.

[27] Rama B., Swanandi P., Vidya T., Bipinraj N. (2011). Developments in Analytical Methods for Detection of Pesticides in Environmental Samples, 2, 1-2.

[28] Rehman, S. Khan, Z. F. Maqbool,T. (2008). Physical and spectroscopic characterization of Pakistani honey, 35, 204.

[29] Soares J., Soares N., Pires M., Novaes S., Lacerda J. (2008). Honey Classification from Semi-Arid, Atlantic and Transitional Forest Zones in Bahia, Brazil, 19, 508

[30] WHO, (1997). Guidelines for predicting dietary intake of pesticide residues (revised). Global Environment monitoring System-Food Contamination and Assessment Programmed (GEMS/Food) in collaboration with Codex Committee Codex Committee on Pesticide Residues. 
Determination of Physicochemical Properties, Heavy Metals and Pesticide Residues of Honey Samples Collected From Walmara, Ethiopia

[31] WHO, (1999). World Health Organization, Geneva. Guidelines for drinking water quality, 2nd Edition. Vol.2, Sydney

[32] Zacharia, J. (2011). Identity, Physical and Chemical Properties of Pesticides, Pesticides in the Modern World - Trends in Pesticides Analysis, 5, 437.

Citation: Deressa Kebebe., et.al.," Determination of physicochemical properties, heavy metals and pesticide residues of honey samples collected from Walmara, Ethiopia", International Journal of Advanced Research in Chemical Science, vol. 6, no. 7, p. 23-33, 2019. DOI: http://dx.doi.org/10.20431/2349-0403.0607004

Copyright: (C) 2019 Authors. This is an open-access article distributed under the terms of the Creative Commons Attribution License, which permits unrestricted use, distribution, and reproduction in any medium, provided the original author and source are credited. 